\title{
Foot Pedal Device
}

National Cancer Institute

\section{Source}

National Cancer Institute. Foot Pedal Device. NCI Thesaurus. Code C49962.

A lever designed to be operated with the foot. 